\title{
Utilization of HFACS - Cognitive Map in Human Error Classification of Ship Collisions in Indonesia
}

\author{
Fadilla I. Prastyasari1 ${ }^{1,2, a, *}$, A.A.B. Dinariyana, Ketut Buda Artana ${ }^{1,2}$, and Dhimas W. \\ Handani ${ }^{1,2}$ \\ ${ }^{1}$ Department of Marine Engineering, Institut Teknologi Sepuluh Nopember, Surabaya Indonesia \\ ${ }^{2}$ PUI Keselamatan Kapal dan Instalasi Laut (KEKAL) \\ a.fadilla@ne.its.ac.id \\ *corresponding author
}

Keywords: Cognitive map (CM); Human factor analysis and classification system (HFACS); Indonesia; Ship accident.

Abstract: Human factor has become the main factor to contribute in the marine accidents for the past few years. This paper proposed a method to classify of the human factor involving in the collision accident as well as finding the most significant factor by using human factor analysis and classification system (HFACS) combined with the cognitive map (CM). This method was used to analyze collision accident reports for the past five years, occurred between 2010 to 2014, in Indonesia. The result from the HFACS was broken down to find the causes of collision. Then, CM was used to model the relationship between each cause. Factors that have the highest global centrality value (GCV) can be said as the most significant factors. The result found that those factors are "Physical \& mental tiredness of crew (PU9)", "Bad medical conditions of crew (PU10)", "Crews onboard are underqualified (US4)", and "Operator ignorance to the crew skills (OI3)" that have GCV as much as 9. This means that these factors affect nine other factors.

\section{Introduction}

Indonesia is an archipelagic country most of its country consists of oceans. This makes shipping line in Indonesia very dense which is dominated by local ferries and merchant ships coming from abroad. Unfortunately, this does not make the maritime safety in Indonesia to be better. It is marked by the number of marine accidents, especially ships' collision. Figure 1 shows the data of marine accidents based on reports published by the Indonesian National Transportation Safety Committee (NTSC). From the graph, it shows that the ship collision is one of the ship's accidents that has the highest frequency. However, there are still many unreported accidents by the NTSC, indicating that the actual number of accidents is higher.

Human factor has been the main factor to contribute in the marine accidents for the past few years. According to United States Coast Guard (USCG) data in 1999 to 2001, human factor gave a contribution to the accidents for about 80 to $85 \%$ and $50 \%$ of it were initiated by human factor while the other $30 \%$ were in relation with human error [1]. In addition, Korean MOMAF also stated that human error had a portion of cause for about $90.3 \%$ and $9.7 \%$ of it was caused by short circuit, defects and the bad weather [2]. Moreover, human factor also became one of three main factors that affecting 
the navigational safety in Taiwanese Harbour [3]. Indonesia itself ratifies numerous regulations which control the seaworthiness to make sure a safe shipping operation. Several aspects that might be related to human factor were taking part in an accident such as marine inspector skill, ISM code auditor skill, port authority, and so on [4]. As the investigation report of accidents in Indonesia published by NTSC shown that most of the them were caused by human factor, thus an evaluation of accident regarding the human factors is needed to find the causal factors involved and to avoid a similar accident to be happened in the future.

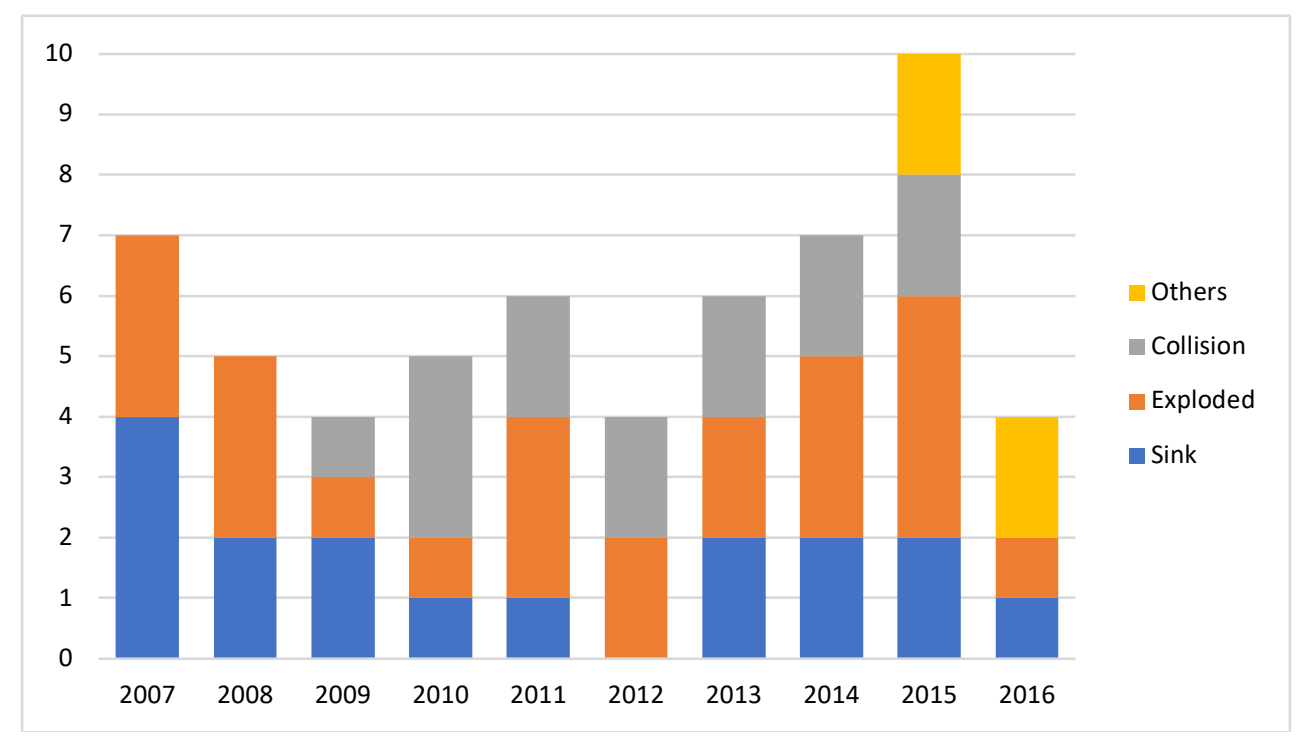

Figure 1: Accident data reported by Indonesian NTSC [5]

Several studies have been revealed the role of human factor and organizational factor that affect the accident occurrence. At the beginning, human factor was found to be a major cause of aviation accident rather than machine failure. Then, study of human factor is further developed to analyze some type of accidents. SHELLO model was applied to assess the human factor in runway excursions [6], meanwhile [7] studied about the human factor analysis in aviation crash accidents. Moreover, some studies in the railroad industries in China [8] and UK [9] showed the importance of human factor.

This paper studies about the classification of the human factors involved in the collision accident in Indonesia for the past five years, occurred between 2010 to 2014. There are 9 events that implicating 19 vessels. The classification will be based on Reason's model Human Factor Analysis and Classification System (HFACS). The analysis carried to find the major factor that causing an accident to happen in Indonesia. Moreover, the factors having been classified further analyzed by using Cognitive Map (CM) in order to find the relationship between factors.

The HFACS is a systemic approach about the human factor classification method based on the Swiss-cheese Model developed by Reason in 1990 [10]. This method has been widely applied to some industry. Namely HFACS-OGI that was used to classifying human factors in oil and gas industry [11], in marine industries and operation, boiler explosions onboard was assessed with HFACS that based on Fuzzy AHP [12]. Those papers show that this classification method is powerful and flexible because it can be combined with another method to get a further result. 


\section{Methodology}

\subsection{Collision Data}

Accident reports were collected from Indonesian NTSC through its website. Only the published reports were used in this paper. The collision reports between 2010 until 2014 were gathered and the summary can be viewed in Table 1 .

Table 1: Collision Data in Indonesia (2010-2014).

\begin{tabular}{|l|l|l|}
\hline Year & Ships involved & Collision area \\
\hline 2014 & $\begin{array}{l}\text { Container ship, General cargo and } \\
\text { Passenger ship }\end{array}$ & Surabaya west access channel \\
\hline 2013 & General cargo and container ship & Near Port of Tanjung Priok \\
\hline 2012 & Container and container ship & $\begin{array}{l}\text { Anchorage area of Port of } \\
\text { Tanjung Perak }\end{array}$ \\
\hline 2012 & Passenger ship and tanker & Sunda Strait \\
\hline 2011 & Ferry and barge & Barito River \\
\hline 2011 & Tanker and fishing vessel & Musi River \\
\hline 2010 & General cargo and general cargo ship & $\begin{array}{l}\text { Pasitanete Island, South } \\
\text { Sulawesi }\end{array}$ \\
\hline 2010 & General cargo and cargo ship & Port of Celukan Bawang \\
\hline 2010 & Tanker and general cargo ship & $\begin{array}{l}\text { North part of the Port of } \\
\text { Tanjung Priok }\end{array}$ \\
\hline
\end{tabular}

\subsection{HFACS for Ship Collision}

HFACS based upon a Swiss-cheese model shows the steps of system failures. This framework is used to analyze and investigate human error in a simple and thorough way. The model itself represents cheeses that have many holes and a failure can happen if the holes line up to make a clear passage. The holes depict the latent failures and the other failure is active failure. This classification consists of four level of the human error causation: (1) unsafe acts, (2) precondition for unsafe acts, (3) unsafe supervision and (4) organizational influences. The last three causes can be indicated as latent failures, while the first is the active failures. Active failure happens at the sharp end of the system and have a direct and immediate result. Meanwhile, latent failure can be in the system for a long time without causing a serious disturbance [13].

The HFACS is divided into 19 categories under those four levels. Unsafe acts comprised of errors (decision errors, skill-based errors, and perceptual errors) and violation (routine and exceptional). Preconditions for unsafe acts divided into three categories, namely environmental factors (technological environment and physical environment), condition of the operator (adverse mental states, adverse physiological states, and physical/mental limitations) and personnel factors (communication, coordination \& planning and fitness for duty). Next is unsafe supervision that consists of inadequate supervision, planned inappropriate operations, failed to correct known problems and supervisory violations. The last is organizational influences that covers organizational climate, operational process and resource management.

This paper made a slight modification to the HFACS model developed in a research that classifying human factors based on HFACS that has been adjusted to the collision accidents [13]. Two categories 
under technological environment on the environmental factors are added. Those two are navigational and technical (machineries). This addition made because in navigational equipment and machineries equipment have a different nature.

The navigational equipment is used to control all activities on the deck by the Captain or Officer of the Watch. Whilst the technical is related with the technology used in the machinery systems in the engine room. This slight change makes the categories used in HFACS become 21 categories but still in four levels. Figure 2 represents the HFACS for Ship Collision used in this paper.

The coding process was carried to analyze which factor in the accident matching with the HFACS. Only the factors that obviously stated in the reports that considered in this analysis to avoid any subjective opinion. This classification will give a result about which factors that have big contribution to the collision accident in Indonesia between 2010 and 2014

\subsection{Cognitive Map (CM)}

Cognitive map is first developed by Tolman to describe the viewpoint of a person [14]. The main idea of this method is to be able to create a decision making on any problem. Many researches have been carried based on the CM to model the way human thinking and reasoning. This method is applied on a paper to model the human factors in the lifeboat drill process in combination with HFACS [15].

The most affecting factor can be inferred from the one that has the biggest centrality value. Centrality values divided into two, global centrality value (GCV) and normalized centrality value (NCV). The GCV is calculated from the total positive or negative relationship for each cause. Meanwhile, the NCV is a normalized centrality value that calculated by level based on each column normalization. Other values that can be obtained from this technique are rank-global centrality value (R-GCV) and rank-normalized centrality value (R-NCV). Both numbers represent the rank of every single cause.

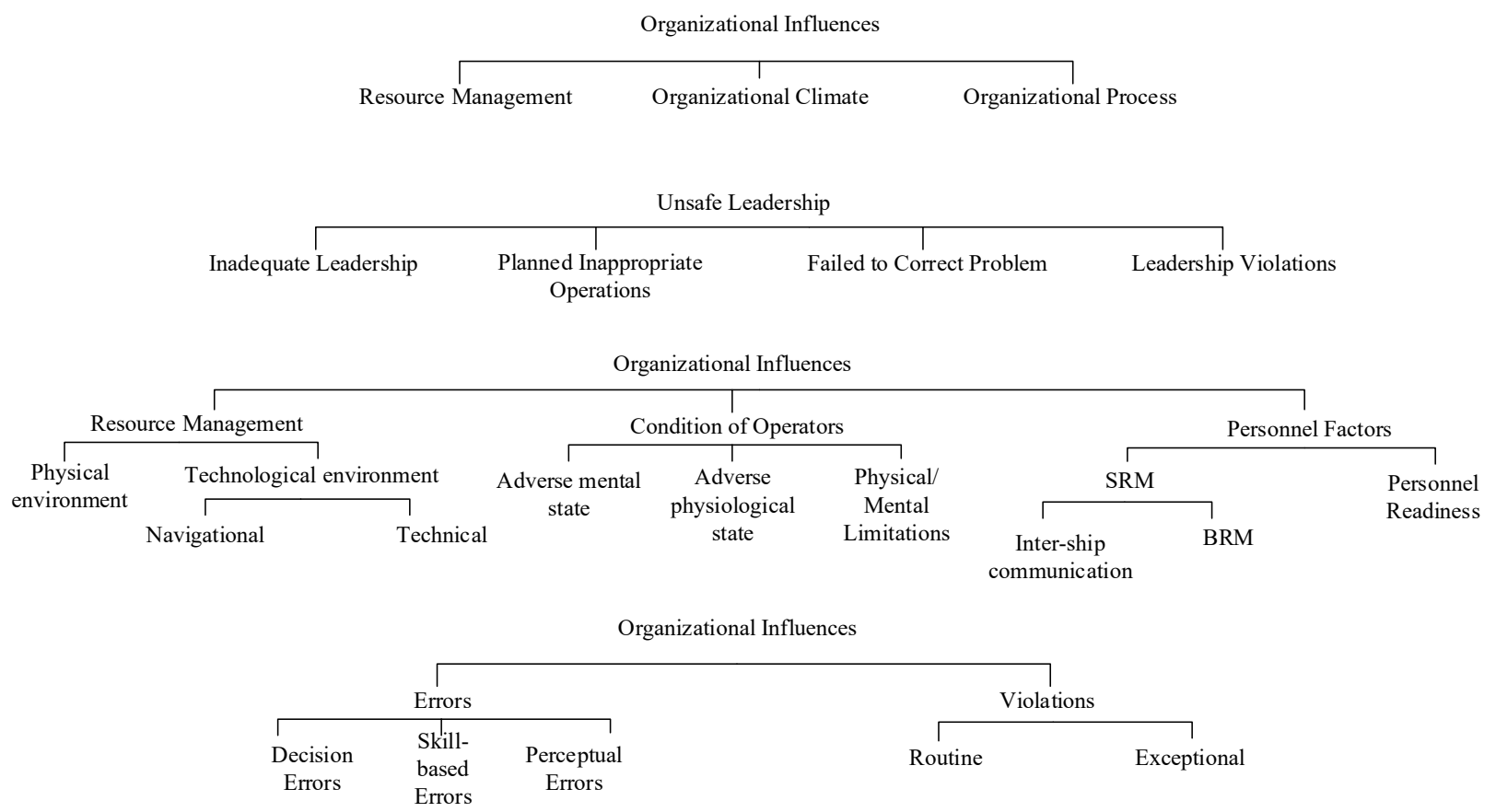

Figure 2: HFACS for Ship Collision. 


\section{Discussion and Result}

Ships involved in nine accidents were general cargo (7), container (4), tanker (3), passenger ship (3), barge (1) and fishing vessel (1). Five collision cases happened in the port area and four accidents happened in the shipping lane.

This paper utilized HFACS framework to classifying the human factors based on the hierarchical levels to know which factors that contributed in the collision accident in Indonesia. Brainstorming was done to identify the factors related to human from the accident report.

\subsection{Classification with HFACS for Ship Collision}

Human factors that have been classified into the four hierarchical levels then broken down into several collision-causes under each level and shown in Table II. These factors which determined from HFACS match with the marine accident environment rather than the factors included in the HFACS that was previously used in the aviation industry.

\subsection{CM analysis}

\section{A. Causal Relation Matrix}

The factors involved are fitted into a matrix to find their relationship. This matrix was filled based on the expert judgements. It makes the relation matrix solely based on the subjectivity of the decision maker. The relationship can be positive, negative, or neutral. For example, "visual disturbance from surroundings (PU4)" will affect "crew poor decision (UA1)", hence they have positive relationship and positive sign is placed in the matrix. Meanwhile, "crew fail to prioritize attention (UA3)" will not affect "bad medical conditions of crew (PU10)", therefore no relationship between these two causes and zero " 0 " is placed. The relationship between all the collision causes need to be analyzed to produce a causal relation matrix of collision accidents that shown in Table III.

\section{B. Calculating the Centrality Value}

One or more accident causes that has highest centrality value can be inferred as the main factor that gives the biggest contribution to the occurrence of an accident. Two values were calculated in this paper, GCV and NCV. The GCV represents the total relationship of each cause in one column globally, while the NCV is the centrality value that has been normalized in each hierarchy level (i.e. "crew poor decision (UA1)" is only normalized with another factors under the unsafe acts category). A neutral relationship is not taken into account to calculate the GCV number. For instance, "Crew misinterpreted/misjudged the ship heading/distance/speed (UA4)" which is under unsafe acts category has a total of five positive values. Hence, the GCV of this cause is five. Whilst, the NCV can be calculated by dividing the GCV of UA4 with the total GCV of unsafe acts category which is seventeen. The NCV then found to be 0.12 or $12 \%$. The summary of all centrality values is shown in Table IV.

\section{Results}

The result of centrality value calculation (GCV and NCV) showing that "Physical \& mental tiredness of crew (PU9)", "Bad medical conditions of crew (PU10)", "Crews onboard are underqualified (US4)", and "Operator ignorance to the crew skills (OI3)" become the central factors because they have the greatest number equals to nine. In contrast, "Crew violated the allowed cargo (UA5)" appears to be the most insignificant factor. These statements can be validated by looking back to the accident reports that some of accidents happened due to physical tiredness and under-qualified crews that lead into the other causes of accident. 
Table 2: Collision causes based on Human Factors Analysis and Classification System

\begin{tabular}{|l|l|}
\hline \multicolumn{1}{|c|}{ Code } & \\
\hline UA & Unsafe acts \\
\hline UA1 & Crew poor decision \\
\hline UA2 & Officer of watch poor technique to avoid the collision risk \\
\hline UA3 & Crew fail to prioritize attention \\
\hline UA4 & Crew misinterpreted/misjudged the ship heading / distance / speed \\
\hline UA5 & Crew violated the allowed cargo \\
\hline UA6 & No sign given to the other ship \\
\hline UA7 & Officer of watch visual illusion \\
\hline PU & Preconditions for unsafe acts \\
\hline PU1 & Crew is not familiar with the shipping lane \\
\hline PU2 & Shipping lane is crowded \\
\hline PU3 & Shallow water condition \\
\hline PU4 & Visual disturbance from surroundings \\
\hline PU5 & Improper use of navigational equipment \\
\hline PU6 & Improper use of machineries \\
\hline PU7 & Bad communication, coordination and planning between crew onboard \\
\hline PU8 & Bad inter-ship communication \\
\hline PU9 & Physical \& mental tiredness of crew \\
\hline PU10 & Bad medical conditions of crew \\
\hline US & Unsafe supervision \\
\hline US1 & Unresponsiveness of the port authority/pilotage office to the ship request \\
\hline US2 & Poor compliance to the pilotage regulation \\
\hline US3 & VTS lack of ability to watch the ship traffic \\
\hline US4 & Crews onboard are underqualified \\
\hline US5 & Lack of abandon ship drill training \\
\hline OI & Organizational influences \\
\hline OI1 & Deficiency of management plan \\
\hline OI2 & Incompliance to the regulation \\
\hline OI3 & Operator ignorance to the crew skills \\
\hline OI4 & Commercial pressure \\
\hline
\end{tabular}

Table 3: Collision causes based on HFACS

\begin{tabular}{|c|c|c|c|c|c|c|c|c|c|c|c|c|c|c|c|c|c|c|c|c|c|c|c|c|c|c|}
\hline & \multicolumn{7}{|c|}{ Unsafe acts } & \multicolumn{10}{|c|}{ Preconditions for unsafe acts } & \multicolumn{5}{|c|}{ Unsafe supervision } & \multicolumn{4}{|c|}{ Org. influences } \\
\hline & UA1 & UA2 & UA3 & UA4 & UA5 & JUA6 & UA7 & \begin{tabular}{|l|} 
PU1 \\
\end{tabular} & \begin{tabular}{|l|} 
PU2 \\
\end{tabular} & \begin{tabular}{|l|} 
PU3 \\
\end{tabular} & PU4 & \begin{tabular}{|l|} 
PU5 \\
\end{tabular} & \begin{tabular}{|l} 
PU6 \\
\end{tabular} & \begin{tabular}{|l|} 
PU7 \\
\end{tabular} & PU8 & \begin{tabular}{|l|} 
PU9 \\
\end{tabular} & PU10 & US1 & US2 & \begin{tabular}{|l|l} 
US3 \\
\end{tabular} & \begin{tabular}{|l|l} 
US4 \\
\end{tabular} & \begin{tabular}{|l|} 
US5 \\
\end{tabular} & \begin{tabular}{|l|} 
OI1 \\
\end{tabular} & \begin{tabular}{|l|} 
OI2 \\
\end{tabular} & \begin{tabular}{|l|}
$\mathrm{OI} 3$ \\
\end{tabular} & $\mathrm{OI4}$ \\
\hline \begin{tabular}{|l|} 
UA1 \\
\end{tabular} & & + & + & + & 0 & + & + & + & 0 & 0 & + & + & + & + & + & + & + & + & + & 0 & + & + & 0 & 0 & + & 0 \\
\hline \begin{tabular}{|l|} 
UA2 \\
\end{tabular} & 0 & & 0 & + & 0 & + & + & + & + & + & + & + & 0 & + & + & 0 & 0 & + & + & + & + & 0 & 0 & + & + & 0 \\
\hline \begin{tabular}{|l|} 
UA3 \\
\end{tabular} & 0 & 0 & & + & 0 & 0 & 0 & 0 & 0 & 0 & 0 & 0 & 0 & + & + & 0 & 0 & 0 & 0 & 0 & 0 & 0 & 0 & 0 & 0 & 0 \\
\hline \begin{tabular}{|l|} 
UA4 \\
\end{tabular} & 0 & 0 & 0 & & 0 & + & + & + & 0 & 0 & + & + & 0 & 0 & 0 & + & + & 0 & 0 & 0 & + & 0 & 0 & 0 & + & 0 \\
\hline UA5 & 0 & 0 & 0 & 0 & & 0 & 0 & 0 & 0 & 0 & 0 & 0 & 0 & 0 & + & 0 & 0 & 0 & 0 & 0 & + & 0 & + & + & + & + \\
\hline \begin{tabular}{|l|} 
UA6 \\
\end{tabular} & + & 0 & 0 & + & 0 & & 0 & 0 & 0 & 0 & + & 0 & 0 & 0 & 0 & 0 & 0 & 0 & 0 & 0 & + & 0 & 0 & + & + & 0 \\
\hline \begin{tabular}{|l|} 
UA77 \\
\end{tabular} & 0 & 0 & 0 & 0 & 0 & + & & 0 & 0 & 0 & + & 0 & 0 & 0 & 0 & + & + & 0 & 0 & 0 & 0 & 0 & 0 & 0 & 0 & 0 \\
\hline \begin{tabular}{|l|} 
PU1 \\
\end{tabular} & 0 & 0 & 0 & 0 & 0 & 0 & 0 & & 0 & 0 & 0 & 0 & 0 & 0 & 0 & 0 & 0 & 0 & 0 & 0 & + & 0 & 0 & 0 & 0 & 0 \\
\hline \begin{tabular}{|l|} 
PU2 \\
\end{tabular} & 0 & 0 & 0 & 0 & 0 & 0 & 0 & 0 & & 0 & 0 & 0 & 0 & 0 & 0 & 0 & 0 & 0 & 0 & 0 & 0 & 0 & 0 & 0 & 0 & 0 \\
\hline \begin{tabular}{|l|} 
PU3 \\
\end{tabular} & 0 & 0 & 0 & 0 & 0 & 0 & 0 & 0 & 0 & & 0 & 0 & 0 & 0 & 0 & 0 & 0 & 0 & 0 & 0 & 0 & 0 & 0 & 0 & 0 & 0 \\
\hline \begin{tabular}{|l|} 
PU4 \\
\end{tabular} & 0 & 0 & 0 & 0 & 0 & 0 & 0 & 0 & + & 0 & & 0 & 0 & 0 & 0 & 0 & 0 & 0 & 0 & 0 & 0 & 0 & 0 & 0 & 0 & 0 \\
\hline \begin{tabular}{|l|} 
PU5 \\
\end{tabular} & 0 & 0 & 0 & + & 0 & 0 & + & 0 & 0 & 0 & + & & 0 & + & 0 & + & + & 0 & 0 & 0 & + & 0 & 0 & 0 & + & 0 \\
\hline \begin{tabular}{|l|} 
PU6 \\
\end{tabular} & 0 & 0 & 0 & 0 & 0 & 0 & 0 & 0 & 0 & 0 & 0 & 0 & & + & 0 & + & + & 0 & 0 & 0 & + & 0 & 0 & 0 & + & 0 \\
\hline \begin{tabular}{|l|} 
PU7 \\
\end{tabular} & 0 & 0 & 0 & 0 & 0 & 0 & 0 & 0 & 0 & 0 & 0 & 0 & 0 & & 0 & + & + & + & 0 & 0 & + & 0 & 0 & 0 & 0 & 0 \\
\hline \begin{tabular}{|l|} 
PU8 \\
\end{tabular} & 0 & 0 & 0 & 0 & 0 & + & 0 & 0 & 0 & 0 & + & + & 0 & + & & + & + & 0 & 0 & 0 & 0 & 0 & 0 & 0 & 0 & 0 \\
\hline \begin{tabular}{|l|} 
PU99 \\
\end{tabular} & 0 & 0 & 0 & 0 & 0 & 0 & 0 & 0 & 0 & 0 & + & 0 & 0 & 0 & 0 & & + & 0 & 0 & 0 & 0 & 0 & 0 & 0 & 0 & 0 \\
\hline PU10 & 0 & 0 & 0 & 0 & 0 & 0 & 0 & 0 & 0 & 0 & 0 & 0 & 0 & 0 & 0 & + & & 0 & 0 & 0 & 0 & 0 & 0 & 0 & 0 & 0 \\
\hline \begin{tabular}{|l|} 
US1 \\
\end{tabular} & 0 & 0 & 0 & 0 & 0 & 0 & 0 & 0 & 0 & 0 & 0 & 0 & 0 & 0 & 0 & 0 & 0 & & 0 & 0 & 0 & 0 & + & 0 & 0 & 0 \\
\hline \begin{tabular}{|l|} 
US2 \\
\end{tabular} & + & 0 & 0 & 0 & 0 & 0 & 0 & 0 & 0 & 0 & 0 & 0 & 0 & 0 & 0 & + & + & 0 & & 0 & 0 & 0 & + & + & 0 & 0 \\
\hline \begin{tabular}{|l|} 
US33 \\
\end{tabular} & 0 & 0 & 0 & 0 & 0 & 0 & 0 & 0 & 0 & 0 & 0 & 0 & 0 & 0 & 0 & 0 & 0 & 0 & 0 & & 0 & 0 & 0 & 0 & 0 & 0 \\
\hline \begin{tabular}{|l|} 
US4 \\
\end{tabular} & 0 & 0 & 0 & 0 & 0 & 0 & 0 & 0 & 0 & 0 & 0 & 0 & 0 & 0 & 0 & 0 & 0 & 0 & 0 & 0 & & 0 & + & + & + & 0 \\
\hline \begin{tabular}{|l|} 
US5 \\
\end{tabular} & 0 & 0 & 0 & 0 & 0 & 0 & 0 & 0 & 0 & 0 & 0 & 0 & 0 & 0 & 0 & 0 & 0 & 0 & 0 & 0 & 0 & & + & + & + & + \\
\hline \begin{tabular}{|l|} 
OI1 \\
\end{tabular} & 0 & 0 & 0 & 0 & 0 & 0 & 0 & 0 & 0 & 0 & 0 & 0 & 0 & 0 & 0 & 0 & 0 & 0 & 0 & 0 & 0 & 0 & & 0 & 0 & + \\
\hline \begin{tabular}{|l|} 
OI2 \\
\end{tabular} & 0 & 0 & 0 & 0 & 0 & 0 & 0 & 0 & 0 & 0 & 0 & 0 & 0 & 0 & 0 & 0 & 0 & 0 & 0 & 0 & 0 & 0 & 0 & & 0 & + \\
\hline \begin{tabular}{|l|}
$\mathrm{OI} 3$ \\
\end{tabular} & 0 & 0 & 0 & 0 & 0 & 0 & 0 & 0 & 0 & 0 & 0 & 0 & 0 & 0 & 0 & 0 & 0 & 0 & 0 & 0 & 0 & 0 & 0 & 0 & & 0 \\
\hline \begin{tabular}{|l|}
$\mathrm{OI} 4$ \\
\end{tabular} & 0 & 0 & 0 & 0 & 0 & 0 & 0 & 0 & 0 & 0 & 0 & 0 & 0 & 0 & 0 & 0 & 0 & 0 & 0 & 0 & 0 & 0 & 0 & 0 & 0 & \\
\hline
\end{tabular}


Table 4: Collision causes based on HFACS

\begin{tabular}{|c|c|c|c|c|}
\hline $\mathbf{F}$ & GCV & R-GCV & NCV & R-NCV \\
\hline \multicolumn{5}{|c|}{ Unsafe acts } \\
\hline UA1 & 2 & 17 & 0.12 & 4 \\
\hline UA2 & 1 & 20 & 0.06 & 5 \\
\hline UA3 & 1 & 20 & 0.06 & 5 \\
\hline UA4 & 5 & 8 & 0.29 & 1 \\
\hline UA5 & 0 & 26 & 0.00 & 7 \\
\hline UA6 & 4 & 8 & 0.24 & 2 \\
\hline UA7 & 4 & 8 & 0.24 & 2 \\
\hline \multicolumn{5}{|c|}{ Precondition for unsafe act } \\
\hline PU1 & 3 & 15 & 0.06 & 7 \\
\hline PU2 & 2 & 17 & 0.04 & 8 \\
\hline PU3 & 1 & 20 & 0.02 & 9 \\
\hline PU4 & 8 & 5 & 0.17 & 3 \\
\hline PU5 & 4 & 8 & 0.09 & 5 \\
\hline PU6 & 1 & 20 & 0.02 & 9 \\
\hline PU7 & 6 & 6 & 0.13 & 4 \\
\hline PU8 & 4 & 8 & 0.09 & 5 \\
\hline PU9 & 9 & 1 & 0.19 & 1 \\
\hline PU10 & 9 & 1 & 0.19 & 1 \\
\hline \multicolumn{5}{|c|}{ Unsafe supervision } \\
\hline US1 & 3 & 15 & 0.19 & 2 \\
\hline US2 & 2 & 17 & 0.13 & 3 \\
\hline US3 & 1 & 20 & 0.06 & 4 \\
\hline US4 & 9 & 1 & 0.56 & 1 \\
\hline US5 & 1 & 20 & 0.06 & 4 \\
\hline \multicolumn{5}{|c|}{ Organizational influences } \\
\hline OI1 & 5 & 8 & 0.21 & 3 \\
\hline OI2 & 6 & 6 & 0.25 & 2 \\
\hline OI3 & 9 & 1 & 0.38 & 1 \\
\hline OI4 & 4 & 8 & 0.17 & 4 \\
\hline
\end{tabular}

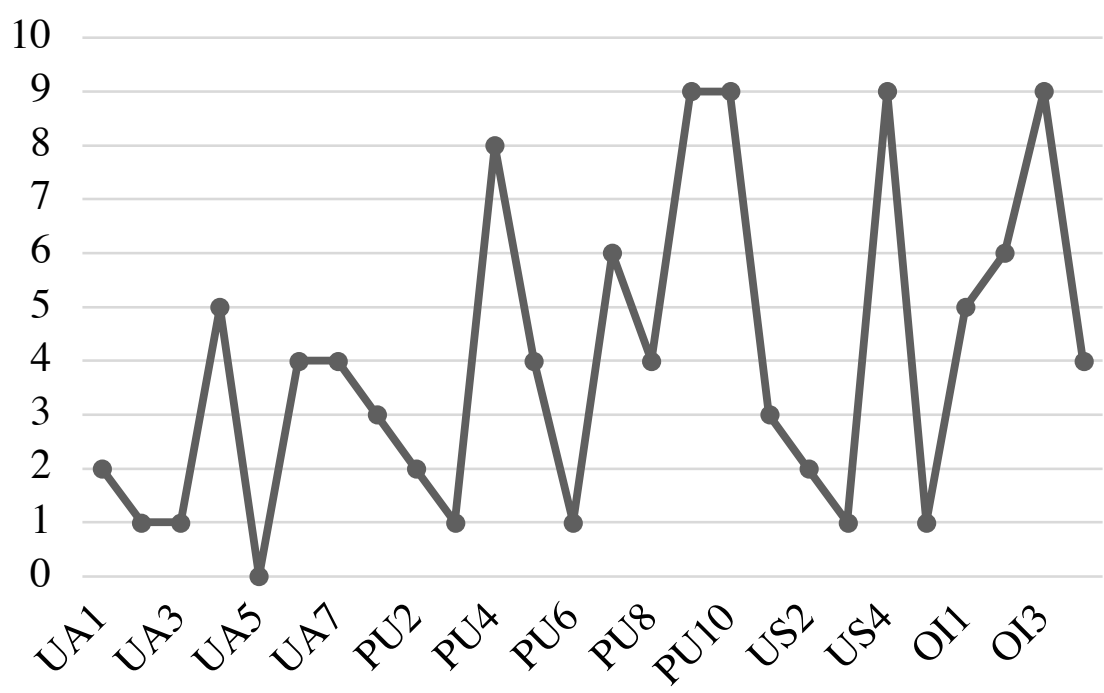

Figure 3. GCV Distribution 


\section{Conclusion}

This research develops an approach to assess a collision accident by utilizing HFACS for Ship Collision with cognitive map. The HFACS for Ship Collision is a modified version of HFACS developed by Reason. This framework is adjusted to the marine collision environment; hence, it becomes more suitable to be applied to this case. The hierarchical factors are broken down into several causes under four categories. Whereas, the $\mathrm{CM}$ is used to modelling the relationship between each cause of collision to find the most contributing factor.

Based on those methods, the conclusions that can be drawn are:

- The HFACS for Ship Collision is applicable to the marine collision in Indonesia.

- The combination of HFACS for Ship Collision and CM is very useful to find relationship of every factors as well as the factor that significantly affects the other factors.

For further researches, prevention actions can be proposed based on the result of this research. By eliminating the most central factor, the other causes can be avoided.

\section{References}

[1] D. B. McCafferty and C. C. Baker, "TRENDING THE CAUSES OF MARINE INCIDENTS," in Marine Incidents 3 Conference, London, 2006.

[2] E. W. Yu, "Human Factors Contributing to Marine Accidents," M. o. O. a. Fisheries, Ed., ed: Australian Government: Maritime Safety Authority.

[3] C.-C. Chou, Y.-L. Su, R.-F. Li, C.-L. Tsai, and J.-F. Ding, "Key Navigation Safety Factors in Taiwanese Harbors and Surrounding Waters," Journal of Marine Science and Technology, vol. 23, pp. 685-693, 2015.

[4] National Transportation Safety Committee, "Final Report of Shipping Accident Investigation: Sinking Accident of KMP. Rafelia 2," 2016.

[5] National Transportation Safety Committee. (2017, 29 January). Accident Reports. Available: http://knkt.dephub.go.id/knkt/ntsc_maritime/maritime.htm

[6] Y.-H. Chang, H.-H. Yang, and Y.-J. Hsiao, "Human risk factors associated with pilots in runway excursions," Accident Analysis \& Prevention, vol. 94, pp. 227-237, 2016/09/01/ 2016.

[7] L. Gong, S. Zhang, P. Tang, and Y. Lu, "An integrated graphic-taxonomic-associative approach to analyze human factors in aviation accidents," Chinese Journal of Aeronautics, vol. 27, pp. 226-240, 2014/04/01/ 2014.

[8] Q. Zhan, W. Zheng, and B. Zhao, "A hybrid human and organizational analysis method for railway accidents based on HFACS-Railway Accidents (HFACS-RAs)," Safety Science, vol. 91, pp. 232-250, 2017/01/01/ 2017.

[9] R. Madigan, D. Golightly, and R. Madders, "Application of Human Factors Analysis and Classification System (HFACS) to UK rail safety of the line incidents, "Accident Analysis \& Prevention, vol. 97, pp. 122-131, 2016/12/01/ 2016.

[10] J. Reason, "Human error: models and management," BMJ, vol. 320, p. 768, 2000.

[11] S. C. Theophilus, V. N. Esenowo, A. O. Arewa, A. O. Ifelebuegu, E. O. Nnadi, and F. U. Mbanaso, "Human factors analysis and classification system for the oil and gas industry (HFACS-OGI)," Reliability Engineering \& System Safety, vol. 167, pp. 168-176, 2017/11/01/2017.

[12] M. Celik and S. Cebi, "Analytical HFACS for investigating human errors in shipping accidents," Accident Analysis and Prevention, vol. 41, pp. 66-75, 2009.

[13] C. Chauvin, S. Lardjane, G. Morel, J.-P. Clostermann, and B. Langard, "Human and organisational factors in maritime accidents: Analysis of collisions at sea using the HFACS," Accident Analysis \& Prevention, vol. 59, pp. 26-37, 2013/10/01/2013.

[14] E. C. Tolman. (1948, Cognitive Maps in Rats and Men. The Psychological Review 55(4), 189-208.

[15] E. Akyuz and M. Celik, "Utilisation of cognitive map in modelling human error in marine accident analysis and prevention," Safety Science, vol. 70, pp. 19-28, 2014/12/01/2014. 